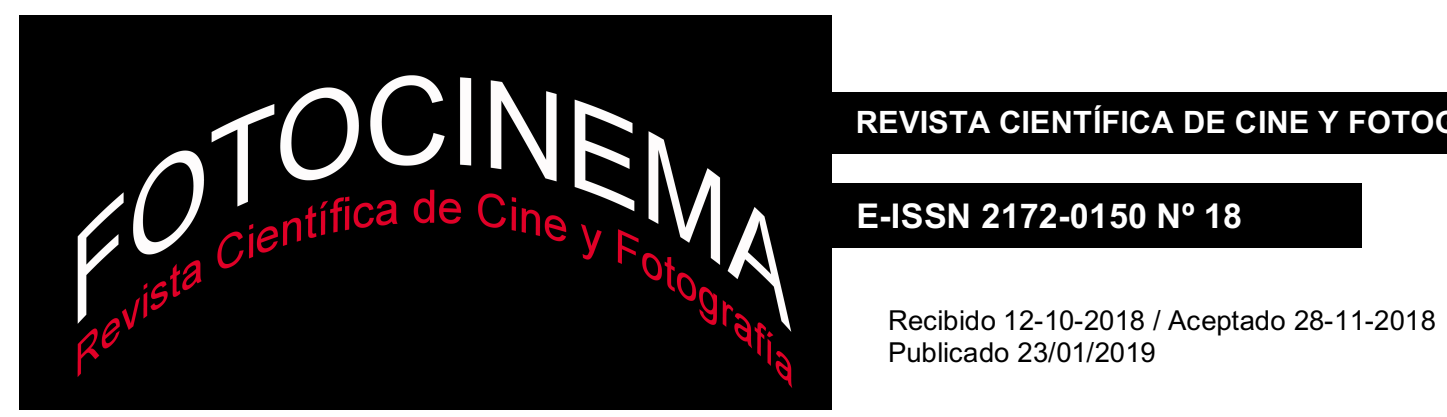

\title{
El uso eficaz de la imagen y la palabra en una reescritura fílmica oleaniana de Tormento
}

\section{The effective use of the image and the word in an oleanian film rewriting of Tormento}

Cristina Jiménez Gómez

Universidad de Córdoba, España

\section{Resumen:} cristti70@hotmail.com

La etiqueta de "adaptación" cinematográfica, que ha sido utilizada históricamente con un sentido peyorativo y corruptor respecto al discurso textual de partida, resulta insuficiente para dar cuenta de los efectos estéticos, técnicos y pragmáticos que se producen cuando la literatura es llevada a la pantalla. Particularmente, la película Tormento (1974) de Pedro Olea, basada en la novela homónima galdosiana de 1884, nos ofrece un campo amplio para indagar cómo el director vasco realiza una valiosa reescritura fílmica a través del uso premeditado de la imagen y la palabra. En el cine de Olea, la palabra ofrece estructura y anclaje al significado de la imagen, lo que permite establecer nuevas narraciones posibles sobre la novela galdosiana y, también, analizar cómo se producen, gracias a sus prácticas cinematográficas, ciertos efectos estéticos que el espectador ha de saber interpretar. Estamos, pues, en la línea de una teoría de la recepción cinematográfica donde el espectador tiene mucho más que decir en la dotación del sentido de la obra artística.

\begin{abstract}
:
The notion of film "adaptation", historically used in a pejorative and corrupting sense with regard to the source text, is insufficient to understand the aesthetic, technical and pragmatic effects that are produced in the translation of literary texts to the screen. Particularly, the film Tormento (Pedro Olea, 1974), based on the homonymous galdosian novel of 1884, offers a wide field to research how the basque filmmaker carries out a valuable film rewriting through the premeditated use of the image and the word. In the oleanian cinema, the word offers structure and anchoring to the meaning of the image, which allows to establish new possible narrations about the Galdosian novel and, also, to analyze how, due to his cinematographic practiques, certain aesthetic effects that the spectator has to know to interpret are produced. Consequently, we place in the line of a film reception theory where the spectator has much more to offer in providing of the artistic work's sense.
\end{abstract}

Palabras clave:

reescritura fílmica; Pedro Olea; palabra; imagen, recepción; espectador

Keywords:

film rewriting; Pedro Olea; word; image; reception; spectator 


\section{Introducción: Literatura y Cine}

En 1974, se estrenó la película española Tormento, dirigida por el cineasta vasco Pedro Olea y protagonizada, entre otros, por Ana Belén, Concha Velasco y Francisco Rabal. Basada en la novela homónima de 1884 de Benito Pérez Galdós, la filmación enseguida se inscribió bajo el membrete de adaptación cinematográfica de un clásico literario con el sentido negativo que para muchos críticos eso conllevaba en el campo de la creación artística. Esto no nos sorprende si tenemos en cuenta que la relación literatura-cine siempre ha sido una cuestión arduamente debatida a lo largo de la historia dado que, desde los orígenes del séptimo arte, son muchas las obras de creación literaria que se han llevado a la gran pantalla. Por ello, no resulta extraño que dicha relación se haya traducido en vínculos y en tensiones, sobre todo, porque, como ya vio Seymour Chatman en Historia y discurso: la estructura narrativa en la novela y en el cine en (1978), ambos medios de expresión - el literario y el cinematográfico- narran historias y presentan una estructura narrativa.

Los problemas se dejaron notar ya desde los orígenes del séptimo arte cuando, en 1895, se daba a conocer por primera vez la existencia del cinematógrafo con los hermanos Louis y Auguste Lumière', tiempo en que la producción literaria llevaba ya muchos años de vida. A partir de aquí, la historia de las relaciones conflictivas entre el arte fílmico y el literario viene marcada por una larga tradición de jerarquías y rivalidades, quizás a causa de la equivocada aspiración de que la adaptación cinematográfica de obras literarias fuese reconocida como arte "sirviéndose del 'barniz intelectual' que le proporcionaba la literatura, pero a costa de alejarse de su verdadera esencia visual y de sus genuinas posibilidades expresivas" (Peña Ardid, 1992, p. 22).

La consideración que durante mucho tiempo ha perdurado sobre la inferioridad y el gen corruptor de la adaptación respecto a su original literario se basaba en la

\footnotetext{
${ }^{1}$ Desde 1892 , los Lumière empezaron a trabajar sobre la posibilidad de fotografiar imágenes en movimiento y, gracias a la invención del cinematógrafo, rodaron su primera película Salida de los obreros de la fábrica Lumière a modo de documental y como testigo objetivo de la vida cotidiana. No será hasta 1896 cuando se realice la primera adaptación cinematográfica del mito de Fausto con el Faust de Lumière.
} 
tesis no solo de la inferioridad divulgadora y reduccionista de los filmes creados a partir de textos literarios sino, también, de las "carencias expresivas del lenguaje cinematográfico [y] sus condiciones de producción y de recepción” (Peña Ardid, 1992, p. 23). Probablemente porque, ya en sus orígenes, el cine acudió a la literatura del melodrama o del folletín decimonónico para atraer a un público popular heterogéneo y ávido de tramas amorosas y aventureras, la desconfianza hacia el nuevo arte fue generalizada entre los escritores quienes veían que el cine podía ejercer un fin usurpador y corruptor sobre sus textos.

Si tenemos que en cuenta que el cine - nacido a principios del siglo XX - es, relativamente, un medio nuevo, la dialéctica entre el arte cinematográfico y literario no tardó en aflorar y ya, en 1957, aparece Novels into Fỉlms de George Bluestone. Este libro, considerado hoy el primer tratado académico sobre la adaptación fílmica, vino a remarcar las características que diferencian a la novela del cine: la primera es un medio lingüístico, que tiene su origen en un público reducido y culto y es obra de un escritor individual mientras que el segundo es un medio visual, apoyado por un público masivo y producto de un trabajo de colaboración en condiciones industriales. Posteriormente, esta dialéctica se desarrolló en trabajos como El cine y la literatura (1966), de Pio Baldelli, donde se explica las cuatro posibles relaciones que pueden darse entre el discurso fílmico y el literario que le sirve de base: la primera es lo que el teórico italiano denomina el saccheggio o el "saqueo de la obra literaria" puesto que se extraen la trama y los personajes literarios e, incluso, se producen procesos de simplificación y de síntesis del diálogo y del número de personajes por mera explotación comercial; la segunda relación es la de que el film está supeditado, en términos de fidelidad, a la obra literaria; la tercera opción es lo que el investigador italiano denomina la mezzadria o la aparcería entre cine y literatura, dado que el realizador intenta completar el texto literario con añadidos cinematográficos; y la cuarta posibilidad corresponde a que el realizador otorga, con su impronta personal, la plena autonomía al filme respecto al texto literario por lo que consigue distanciar la obra literaria del film.

No obstante, a partir de 1920 y lejos de esta naturaleza corruptora que se ha venido considerando sobre la adaptación cinematográfica, algunos autores formalistas soviéticos incidieron ya en el carácter propiamente narrativo y en los 
elementos del lenguaje del cine. La existencia de un "lenguaje poético" del cine ha sido objeto de interés en teóricos más tardíos como Roman Jakobson, Pasolini famosa fue la polémica teórica entre este autor y Éric Rohmer recogida en el ensayo Cine de poesía contra cine de prosa en 1970 por la editorial Anagramao Christian $\mathrm{Metz}^{2}$ dándose lo que algunos formalistas soviéticos denominaron Poetika Kino ("poética del cine”) que no era sino consecuencia de la transposición de los recursos literarios al medio cinematográfico. Ya Viktor Sklovski diferenciaría, con ocasión del análisis de las películas mudas de Charles Chaplin, Una mujer de París (1923), y de Dziga Vertov, La sexta parte del mundo (1926), entre un cine de prosa y un cine de poesía:

La diferencia fundamental entre poesía y prosa estriba tal vez en una mayor geometría de los procedimientos, en que toda una serie de soluciones semánticas fortuitas es sustituida por una solución geométrica puramente formal. [...] El filme de Chaplin Una mujer de París evidentemente forma parte de la prosa, fundamentada en elementos semánticos, en cosas explícitas. La sexta parte del mundo, aunque sea un encargo del Comercio de Estado, es un poema patético. $L a$ madre [film de Pudovkin] es un singular centauro [...]; el filme comienza en prosa, con intertítulos convincentes que se insertan bastante mal entre los encuadres, y termina en poesía puramente formal. Los encuadres, la repetición de las mismas imágenes, su simbolismo, sustentan mi convicción sobre la naturaleza poética de este filme (Sklovski en F. Albèra (Comp.), 1998, pp. 136-138).

La presencia estructuradora de la palabra incluso en el seno de un medio calificado como "cine mudo", donde los intertítulos o los rótulos con texto iban intercalados entre los fotogramas de la película, resultaba paradójica por esta mezcolanza entre lo visual y lo verbal. No obstante, el teórico soviético Boris Eikhenbaum (en F. Albèra (Comp.), 1998, pp. 45-75) ya vio esta relación y propuso la noción de "discurso interior" para explicar cómo una serie de signos icónicos que aparecen en pantalla tiene su conexión en la mente del espectador. Esto se observa, sobre todo, con la técnica cinematográfica del montaje puesto

\footnotetext{
${ }^{2}$ En sus trabajos "Le cinéma: langue ou langage" (1964) y "Problemas actuales de teoría del cine" (1967) estudia, cómo a partir del montaje, el artista manipula y transforma los elementos de la realidad para aportar su propia visión de esta. Es el cineasta quien decide qué distancia, ángulo y encuadre de la cámara toma sobre los objetos proyectados en aras de producir determinadas imágenes y unos efectos artísticos precisos en el espectador.
} 
que el espectador debe encadenar mentalmente los planos entre sí, captar el significado del episodio y traducirlo al lenguaje de un discurso interior.

Esta nueva concepción del arte cinematográfico que venía dándose hacia mediados del siglo XX da cuenta de cómo la palabra y la imagen están indisolublemente unidos en el medio artístico en tanto que, al igual que la buena literatura hace ver a la mente del lector las palabras por medio de imágenes mentales, una buena película provee de significados nuevos a la mente del espectador a partir de los ángulos y los encuadres de la cámara. En relación con esto, resulta muy apropiado el estudio de 2008 de Darío Villanueva, Imágenes de la ciudad: poesía y cine, de Whitman a Lorca, donde estudia las convergencias entre poesía y cine a partir de las vanguardias y con respecto al tratamiento de la ciudad. Las relaciones recíprocas entre ambos medios de expresión hacen notar que la poesía, por medio de los códigos verbales, era capaz de construir imágenes tan plásticas y expresionistas como las fílmicas y que el cine, por medio de los códigos visuales, era capaz de extrapolar los versos de poetas. Así pues, para Villanueva (2008, p. 107), la urbe en la película El hombre de la cámara (1929) de Dziga Vertov, se plasma en:

imágenes de alto valor expresivo y visual potenciadas por una sintaxis de dinamicidad extrema [...y] haciendo uso del montaje metafórico, semánticamente marcado, [dado que] a las instantáneas de un parto auténtico se contraponen planos de un cementerio; a la escena de una boda, la visita de una pareja rota al registro de divorcios; a la mujer que es atendida en un salón de belleza, el retrato de una trabajadora a la que su oficio ensucia.

Es a partir de aquí cuando los estudios sobre una teoría de la recepción cinematográfica -E. Gómez López (2010, pp. 245-255) propone estudiar la adaptación fílmica desde la Teoría de la Recepción en tanto que el espectador se convierte en autor de una nueva obra en otro medio diferente al literario, el cineirán tomando cuerpo y la importancia de la actividad del espectador se hará cada vez más visible. Ello se pone de manifiesto en el libro Sobre la adaptación y más allá: trasvases filmoliterarios, coordinado por Pedro J. Pardo y Sánchez Zapatero en 2014. 


\section{Hacia una experiencia estética cinemática: el Tormento de Pedro Olea}

A partir de los años 50 del siglo XX, surgirán voces que hablan del cine desde una perspectiva pragmática. André Bazin (2004, p. 185) alude a ciertos contenidos pragmáticos en el arte cinematográfico cuando se pregunta sobre si “el cine está obligado a la representación [...] de una realidad verosímil cuya identidad con la naturaleza, tal como la conoce, pueda admitir el espectador”. No será hasta algunas décadas después, en los años 80, cuando de forma más clara Gianfranco Bettetini surja como representante de una posición semiótico-pragmática. El teórico italiano (1984, pp. 80-102) advierte, por primera vez, que la traducción de un texto de un sistema semiótico a otro no puede quedar reducida "a la traslación de su universo semántico" sino que "debe preocuparse de sus componentes pragmáticos" puesto que todo texto es la manifestación de una estrategia comunicativa y, por tanto, su “traducción” exige la restauración de las instancias que participan en la enunciación.

Los trabajos que se han desarrollado en tiempos más recientes sobre la adaptación cinematográfica se orientan en superar los estudios comparatistas obstinados en medir las convergencias y/o desvíos que se producen en el paso de la literatura a la pantalla. Ya Pérez Bowie, en el magnífico capítulo "La adaptación como encrucijada" de su libro Leer el cine: la teoría literaria en la teoría cinematográfica, da cuenta de la necesidad de sustituir la etiqueta de “adaptación”, tradicionalmente vinculada a resaltar las limitaciones expresivas y creativas del séptimo arte:

La introducción de nuevos términos (traducción, traslación, versión, transposición, transformación), no es sino síntoma de las dificultades que entraña el acercamiento a un fenómeno que no se deja atrapar por esquemas reductores. [...] Aunque la etiqueta "adaptación" sigue manteniéndose por razones de pura inercia, hay quien propone, con razones fundadas, sustituirla por la de "recreación", dado que en la transformación fílmica de un texto literario precedente no cabe hablar de la superioridad de éste, sino de una igualdad entre lenguajes diversos, por lo que el paso de una estructura significante a otra implica también que se modifique la estructura de la significación (2008, p. 186).

En este dilema conceptual, Darío Villanueva (2008, pp. 51-84), en su análisis del filme Pascual Duarte (Ricardo Franco, 1975) respecto al texto original de Camilo 
José Cela, escogerá el concepto de transducción que ya originariamente aplicara L. Doležel en su "Semiótica de la comunicación literaria” a finales de los años 80 del siglo XX. El teórico checo hace referencia al concepto de transducción en su texto "Semiotics of Literary Communication" que, publicado primeramente en la revista italiana Strumenti Critici en 1986, después aparecerá con escasas variaciones en su libro Occidental Poetics. Tradition and Progress de 1990. En este último, Doležel (1990, pp. 167-169) reitera que, frente a los textos no literarios cuya transmisión en las cadenas de circulación es más corta o limitada, los textos literarios están en perpetua transmisión en tanto que la comunicación literaria no acaba en la recepción del texto, sino que aquella puede proyectarse en otros textos de épocas distantes bien en el proceso de la interpretación o, bien, de la creación literaria. Por lo tanto, la proyección de un texto literario en un medio como el cinematográfico puede producir y generar nuevas lecturas que obedecen igualmente a la pericia del realizador y a la competencia y coyuntura de cada espectador.

Se entiende, pues, que la noción de adaptación cinematográfica es incorrecta y da lugar a la confusión, hecho que ha puesto de manifiesto Cepedello Moreno (2011, pp. 179-191) quien llega a hablar de la imposibilidad de la adaptación debido a los obligados reajustes que conlleva el paso de los modos de narrar literarios a los fílmicos. En este sentido, estudios recientes como el de Díaz Navarro (2016, pp. 69-84) desechan la idea de la adaptación fílmica como un producto secundario y reiteran el cine como "un modo de escritura con unos valores estéticos propios (imagen, utilización de planos, temporalidad, etc.)” (p. 70). También González de Canales Carcereny (2017, pp. 83-98) explora y cuestiona el concepto de "adaptación" en el cine de Albert Serra demostrando cómo el director catalán lleva a cabo un proceso de apropiación y reinterpretación fílmica de los clásicos literarios. En la misma línea, Patrick Quinn (2017, pp.4357) habla de "transformación" cuando analiza la película de Luis Buñuel Ensayo de un crimen. La vida criminal de Archibaldo de la Cruz de 1955 a partir de la novela Ensayo de un crimen (Rodolfo Usigli, 1944). Por su parte, I. Gómez y J. M. González Álvarez (2017, pp. 5-18) van más allá de las relaciones entre literatura y cine y entienden la adaptación como un concepto amplio dado el contexto actual de consumo intermediático en el que vivimos. 
Por todo ello, en los últimos tiempos, no sorprende que el término de reescritura haya aparecido con fuerza y de forma reiterativa especialmente cuando se habla de cine donde se "trasciende con creces los procesos de traslación de un texto literario a la pantalla para convertirse en una actividad omnívora que determina las relaciones del cine con las otras artes y con todos los medios de expresión” (Pérez Bowie, 2010, pp. 27-28). Una reescritura es precisamente lo que hace el director Pedro Olea en su película de 1974 Tormento que, objeto de estudio en varios trabajos 3 , literariamente contaba ya con elementos suficientes para plantear una crítica de una sociedad española donde la censura franquista, si bien en sus últimos tiempos -B. Zecchi la llamará "dictablanda" (2012, p. 149)-, todavía se dejaba sentir en el cine tal como estudia Ramón Navarrete-Galiano en su monografía Galdós en el cine español de 2003. Así pues, aunque Tormento obtuvo un importante éxito de taquilla con una recaudación cerca de 730.000 euros y más de 2.000.000 de espectadores según el ICAA del Ministerio de Educación, Cultura y Deporte de España, Olea tuvo que hacer frente al rechazo y a la ideología intransigente que aún perduraban como demuestran sus propias palabras:

No creo en la apertura [...]. Los problemas actuales son imposibles de tratar aquí. Tormento se hizo porque contaba una historia pasada. Una de las sugerencias de la censura, de esas que se reparten sin papel oficial del Ministerio, me aconsejaba no actualizar la historia (Gubern, 1981, p. 272).

Navarrete (2015, pp. 35-44) en otro de sus trabajos explica que, precisamente, las adaptaciones de las novelas de Galdós, en total fueron hasta doce las que se realizaron, no fueron especialmente bien recibidas durante la dictadura franquista porque:

eran consideradas argumentos que contravenían las normas morales del momento, además de las connotaciones anticlericales y seudosocialistas que tenía la persona del creador canario. Por ello durante cerca de treinta años no se llevó ningún argumento de Galdós al cine y cuando se intentó la Censura Franquista frustró la realización (2015, p. 35).

\footnotetext{
${ }^{3}$ La relación de la película oleaniana respecto al texto literario galdosiano de partida ha sido estudiada por $\mathrm{M}^{\mathrm{a}}$ del Mar Mañas Martínez en 1990 con "Benito Pérez Galdós y Pedro Olea: dos visiones para un mismo Tormento" y, más recientemente en 2005, por Teresa $\mathrm{M}^{\mathrm{a}}$ Pol Galiñanes con "Un Tormento literario, un Tormento cinematográfico: la novela de Galdós y la versión de Pedro Olea".
} 
En este contexto político y social, Pedro Olea supo sugerir nuevos matices a través del lenguaje fílmico que, metafórico y sugestivo, se sirve de la palabra para dar anclaje a la imagen y, así, evocar o comunicar connotaciones a las que la mente del espectador debe llegar. Esto nos lleva directamente a hablar de una teoría de la recepción cinematográfica en Olea porque las técnicas cinematográficas utilizadas por el realizador guían los modelos mentales que los espectadores llevan a cabo cuando se sumergen en ese mundo de ficción y participan de la experiencia cinemática. Al igual que la literatura, el séptimo arte depende de los mismos procesos cognitivos que se dan tanto en la creación como en la recepción de aquella porque, pese a su riqueza visual, el cine también está supeditado a las directrices artísticas de una persona que puede proyectar objetos ambiguos, insólitos y sorprendentes según los ángulos, los planos y el encuadre de la cámara con objeto de inferir determinados significados en el público. Ya Bárbara Zecchi (2012, pp. 23-24) apunta hacia una teoría de la recepción cinematográfica cuando sostiene que hay que tener en cuenta los condicionantes ideológicos y el contexto socio-histórico y político en el que se produce la cinematización.

Pedro Olea no solo actualizó la obra, sino que la transformó magistralmente a partir de la técnica del montaje, el movimiento y angulación de la cámara para enfocar los gestos y expresiones de los personajes, la superposición y significación metafórica de los planos cortos y los planos detalle y el poder de la palabra hablada para manifestar el deseo, la ira, la envidia, los celos y la hipocresía. Por consiguiente, los efectos producidos en el filme Tormento dan cuenta de la genialidad de Olea para estimular la actividad cognitiva del espectador respecto a las cosas que no son dichas sino sugeridas en su película, lo que está en estrecha relación con la estructura apelativa de los textos literarios que estudió Iser (en R. Warning (Ed.), 1989, pp. 133-148) algunos años antes. En este sentido, Chatman, que analiza comparativamente la forma narrativa en novela y cine, explica las sensaciones y los significados que la técnica del montaje cabalgado y la cámara lenta en dos películas de Eisenstein evoca en el espectador, técnica que cumple la misma función que las palabras repetidas y parafraseadas en la obra literaria:

Con el montaje cabalgado, parece que los puentes se abren interminablemente. La frustración de la derrota es acentuada por la repetición de la imagen de un caballo muerto, que había tirado de un carro bolchevique colgando grotescamente del centro del puente, que está completamente [...]. La misma técnica se usa en la 
famosa secuencia de la escalinata de Odessa en El Acorazado Potemkin, en la que se alarga la experiencia del espectador del descenso de los soldados hasta hacerla insoportable (Chatman, 1990, pp. 76-77).

En este contexto, veremos cómo Olea, en su película, conjuga de forma extraordinaria códigos icónicos y verbales 4 mediante los cuales evoca y refuerza en el espectador la idea de una sociedad que estaba pidiendo nuevos aires de libertad y otras maneras de relacionarse con las cosas y el mundo.

\section{Una simbiosis perfecta: la palabra y la imagen en el cine de Olea}

En el cine de Olea y, especialmente, en su Tormento, la palabra y la imagen de complementan perfectamente a partir de los juegos metafóricos y elípticos que sugiere el enfoque de la expresión de un rostro, un gesto o un movimiento en los personajes. Pero no solo captamos qué, cómo y por qué sienten los personajes a partir de lo que una imagen nos sugiere simbólica y metafóricamente, sino que, también, lo hacemos por medio de lo que explícitamente la palabra hablada y pensada expresa en el mundo fílmico de Olea.

\subsection{El lenguaje kinésico y las técnicas del zoom y travelling}

La comunicación no verbal en la que las expresiones corporales visibles expresan determinados significados está muy presente en la película oleaniana. Ya sea en lugar del habla o en conjunción con ella, la mirada, los gestos como el movimiento de las manos, la cara y otras partes del cuerpo comunican y refuerzan sentimientos y pensamientos desde el desprecio y la hostilidad hasta el afecto e, incluso, la hipocresía. Intuir esta función kinésica por parte del espectador es esencial para desentrañar el significado último del filme, especialmente, en uno donde se ha subrayado la magistral interpretación de Concha Velasco quién "ofreció una de las mejores composiciones de la codicia y la envidia que ha registrado el celuloide" (Perales, julio de 2013).

\footnotetext{
${ }^{4}$ Ma A. Hermosilla Álvarez (1992, pp. 315-330), de forma inversa, ya analizó cómo los códigos visuales del arte cinematográfico han influido en la escritura literaria. A partir del estudio de los relatos de Ignacio Aldecoa, la autora demuestra cómo el escritor va retratando, igual que si portara una cámara sobre sus hombros, un día laboral de dos camioneros mediante descripciones físicas muy plásticas, el punto de vista de los personajes y las sensaciones y gestos de estos. El cine y la literatura, pues, se hallan vinculados más allá de las adaptaciones y los códigos de uno y otro medio de expresión se entrecruzan.
} 
La primera escena que vemos es la de Rosalía y su marido Francisco de Bringas yendo en coche de caballos para recoger a su primo Agustín, que regresa de las Indias. Rosalía se nos presenta inmediatamente como una mujer que domina a su marido y que no duda en ordenar apresurarse al cochero ante su tardanza. Esta escena, que no aparece en la novela - aquí, la primera vez que tenemos noticia del primo es cuando Rosalía se queja ante Francisco y espera que Agustín pague el colegio y el piano de su hija Isabelita y, poco después, aquel aparece en la casa de los Bringas-, está representada por un plano medio corto y con la cámara objetiva. La focalización externa de la cámara introduce de tal modo al espectador en la situación fílmica que parece que él también vaya montado en el coche de caballos.

La autoridad de Rosalía se deja notar especialmente sobre su marido a quien echa una mirada de reproche y culpabiliza de la tardanza del vehículo. Pero la personalidad intransigente y examinadora de la señora continuará una vez todos lleguen a la estación de tren y se potenciará aún más con el uso del primer plano que descubre a Agustín. Interpretado por el actor Francisco Rabal, vemos a un hombre de mediana edad, de tez morena y vestido con traje de lino marrón, chaleco adornado, lazo y sombrero que se asoma por la ventanilla del tren intentando comprehender todo aquello que se le mostraba a sus ojos.

Sin duda, la función de la cámara que en un movimiento corto recoge y potencia la mirada de Agustín, es imprescindible para significar la extrañeza y el desconcierto de un hombre rústico y asocial venido de las Américas. Su mirada y punto de vista contrastan con los de Rosalía en el momento en que el plano americano o plano medio largo se sitúa sobre la dama burguesa y nos deja ver su entrecejo fruncido, las manos unidas a la altura de su vientre y las pequeñas inclinaciones corporales hacia un lado $\mathrm{u}$ otro con las que intentaba visionar o adivinar mejor la figura del indiano.

La iluminación, junto los movimientos y gestos corporales en los personajes, también es una técnica que Olea utiliza para reforzar la idea de codicia y deseo en aquellos. Así pues, el plano frontal y subjetivo, donde vemos a los Bringas y a Agustín conversando en la recepción del hotel Continental como si el recepcionista que los atiende llevara la cámara, da paso rápidamente al plano detalle donde vemos las manos de Rosalía, ya en su casa, abriendo la caja con el 
collar que su primo le acababa de regalar. Enseguida, la cámara fija en el collar asciende con un movimiento de rotación hacia el rostro de Rosalía que, en un primer plano, se nos muestra iluminado gracias a los ventanales del gabinete y nos deja ver su expresión de regocijo y de placer ante la posibilidad de lucir tan valiosa joya.

Sin embargo, unos instantes después, mientras Rosalía se está mirando ante el espejo deleitándose con su nueva adquisición, el plano general se rompe con el primer plano de Amparo que, inesperadamente, corre las puertas del gabinete y capta la atención de Agustín. Se suceden, en un movimiento rápido de la cámara, los primeros planos entre la joven y el pariente de los Bringas que reflejan tanto la gran impresión de este como el cruce de miradas entre ambos. El impacto que la aparición de Amparo origina en el otro se plasma muy bien gracias a la luminosidad que entra por los ventanales de la estancia. Agustín, que se había levantado para abrochar el collar a Rosalía, queda situado ahora junto a los ventanales de modo que su rostro es iluminado y sus ojos muestran curiosidad y deseo por aquella mujer desconocida.

Pero si hay una secuencia donde por excelencia se plasma la esencial función del lenguaje kinésico y el movimiento de la cámara es la que cierra la película en la estación de tren. El uso del zoom y del travelling compensado en esta escena, procedimiento mediante el cual la cámara se desplaza hacia adelante a la vez que se ajusta el zoom para abrir el plano, nos transmite el impacto que provoca en Rosalía el ver, de repente, a Amparo asomarse por la ventanilla del tren. Aquella, que creía roto el compromiso matrimonial entre el indiano y la joven huérfana, estaba encantada, en un principio, con ver marchar solo a Agustín.

Esta escena final añadida por Olea, dado que en el texto galdosiano se resuelve únicamente con la despedida benévola de Francisco en la estación y la crítica de Rosalía a posteriori en la intimidad de su casa, carga de un fuerte dramatismo y plasticidad a la película. La contraposición de los primeros planos de Rosalía y Amparo no contribuye sino a potenciar la tensión de una situación que frustra la aspiración de la primera de casar, en unos cuatro o cinco años, a su hija Isabel con Agustín y que otorga la victoria a la segunda. La mirada de resentimiento y los dientes apretados $(\mathrm{F} 1)$ de la señora acompañan a las palabras que, dirigidas hacia la joven, salen por su boca de forma abrupta: “iputa, puta, puta!”. 
Paralelamente, la sensación de derrota y venganza, pero también de ira sobre Rosalía queda reforzada por el uso de la técnica del travelling hacia atrás y la puesta en marcha del tren que llevará a los dos amantes hacia Burdeos (F2).

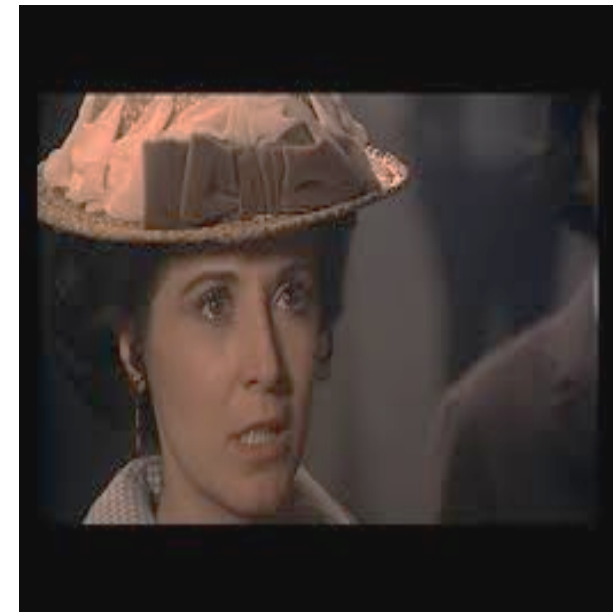

$\mathrm{F} 1$

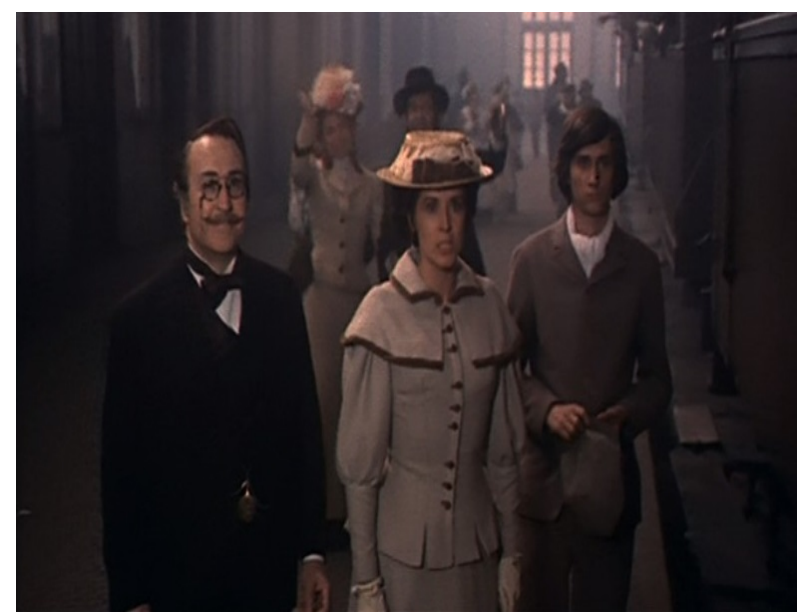

F2

\subsection{La escritura epistolar y la voz en off}

Generalmente las narraciones verbales disponen de mecanismos para expresar los pensamientos, sensaciones y sentimientos más íntimos de los personajes. La introspección psicológica se plasma en literatura y en teatro a través del monólogo interior, el fluir de la conciencia y el soliloquio, ya sea cuando un personaje habla consigo mismo en voz alta o cuando se describe una corriente aleatoria de reflexiones y pensamientos de aquel. Por el contrario, en el cine, la técnica de la voz en off o la voz superpuesta contribuye a clarificar los pensamientos, intenciones y motivaciones más escondidos de los personajes, pero también para incorporar la instancia narradora en pantalla.

En la película de Olea, es muy significativa la secuencia donde tiene lugar la segunda visita de Agustín a la casa de los Bringas. En el momento en que Rosalía y el indiano ya están sentados en el gabinete hablando sobre las clases de piano para Isabelita, tras ser interrumpidos primero por el cobro del carbonero y después por los niños que querían conseguir unos centavos del indiano y comprar helados, se escucha de fondo la música evocadora de un organillo que se toca en la calle. Simultáneamente, aparece el primerísimo primer plano de Rosalía que capta su rostro y nos deja ver su característico ahuecamiento de nariz, descrito en el texto galdosiano como símbolo de su ambición y petulancia. La voz en off de Rosalía, quien se muerde el labio inferior mientras mira fijamente a un Agustín 
embelesado por la melodía proveniente de la calle, nos muestra la verdadera motivación que se esconde tras la amabilidad de aquella hacia su primo: "Si yo tuviera poder para quitarle al primo unos años y ponérselos a la niña... iqué boda, Santo Dios! iQué boda!”

Por el contrario, en otros casos, el procedimiento de la voz en off se construye en conjunción con los códigos verbales de la escritura epistolar que no es sino la palabra pensada de un individuo. Este es el caso de la escena en la que Marcelina Polo escribe una carta a su hermano el cura Pedro Polo, quien permanece recluido en un convento de Toledo en aras de evitar caer de nuevo en placeres carnales con Amparo. Mientras la viuda escribe la carta, se escucha su voz dirigiéndose y contando a su hermano la noticia de que su antigua amante va a casarse con un pariente adinerado de los Bringas (F3).

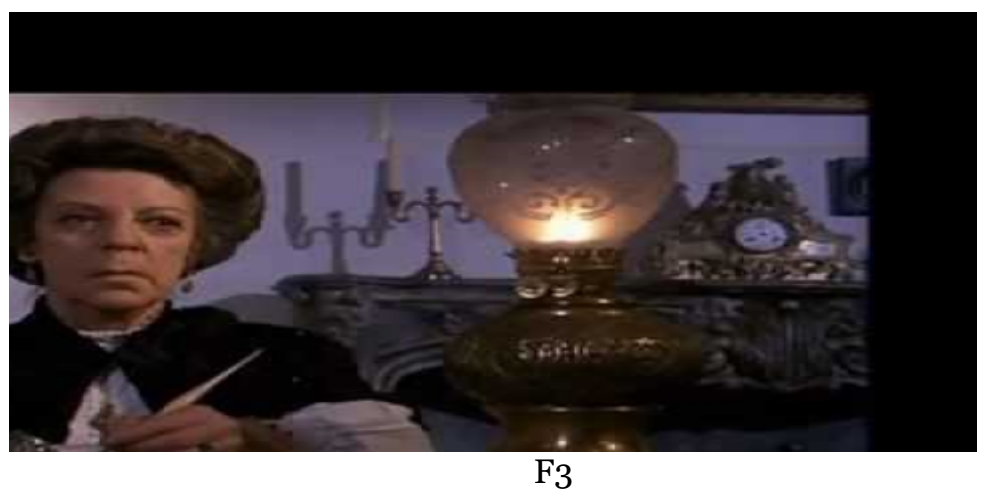

Nos adentramos con cámara subjetiva en la sala de Marcelina Polo y visualizamos la estancia desde un plano medio y más amplio hasta un plano medio corto que encuadra, desde la cabeza hasta el torso, a la viuda sentada y escribiendo. Aquí, la escritura se combina con la voz epistolar superpuesta de su escritora en tanto que, si bien en este caso Marcelina está visualmente delante de la cámara, se retransmite su relato interior de los acontecimientos. Al mismo tiempo, la acción, que sucede en la intimidad y silencio de la casa, queda perfectamente construida gracias a la única iluminación que proporciona un quinqué.

Vemos, por tanto, cómo el cine oleaniano juega con códigos verbales y visuales, donde la palabra y la imagen se refuerzan mutuamente para plasmar los puntos de vista, las sensaciones y los pensamientos más íntimos de los personajes. 


\subsection{El paso del tiempo y la imagen fotográfica}

Las posibilidades que brinda la literatura para expresar el paso del tiempo son ampliamente conocidas. A diferencia de las artes estáticas, como la fotografía o la pintura, la literatura narra escenas desarrollando acciones a través del tiempo. Mediante la manipulación de los segundos, días y años en literatura, el escritor puede comprimir o dilatar la duración de las acciones de la trama y, también, gracias a los saltos temporales, puede modificar el orden de los eventos y retrotraer o adelantar la acción al pasado o al futuro.

En su filme, Olea explota muy bien la técnica literaria del flashback con el sueño erótico que tiene Amparo donde recuerda el momento amatorio vivido con el cura Pedro Polo. Al plano detalle que enfoca las manos de la joven cubriendo los pedazos rotos de la carta que el cura le acababa de enviar, le sucede la escena de cama durante el sueño nocturno de la joven. A diferencia del texto galdosiano donde se sobreentiende la relación carnal pasada, la cámara utiliza un plano perfil para mostrarnos la sensación placentera de los amantes en la cama. Si, en este caso, el objetivo de la cámara capta la plasticidad de un instante en el pasado, después, la combinación de códigos visuales (fotografía) y verbales (palabra) captarán unos momentos vitales que transcurrieron a lo largo de los años.

El ejemplo de esto sucede cuando Pedro Polo comienza a relatar su vida a Amparo, que ha acudido a la vivienda de aquel para convencerle de que la dejara en paz. Mientras el cura le va relatando la historia de su vida (la miseria familiar, la elección de la carrera eclesiástica por necesidad, su expulsión del primer destino en un convento y la clausura de la escuela que abrió en un pueblo), se van visionando una serie de fotografías que atestiguan sus palabras. El primer plano del cura se torna en un plano dorsal donde se ve a Amparo, de espaldas, limpiando las fotografías colgadas en la pared mientras se escucha la voz de Pedro. A la vez que este va manifestando verbalmente cada uno de los momentos de su vida, el efecto del travelling muestra una foto del cura con las monjas del convento seguida de otra foto suya con unos niños en la escuela (F4).

Las imágenes fotográficas, por consiguiente, rescatan la memoria del cura sobre la historia de su vida a la vez que sirven para dar soporte a sus palabras con las que intenta persuadir y conmover a la joven Amparo. Además, la incorporación de Pedro Polo como narrador en primera persona de su propia vida dota al filme 
de una gran carga sentimental y tensión dramática porque hay una exteriorización de la idea de dolor en el sacerdote que se refuerza con el ángulo o la posición de la cámara. Vemos cómo se suceden y se invierten los planos escorzo de manera que, una vez, Pedro, que habla, está de cara y Amparo, que escucha, está de espaldas y, después, cuando la joven responde a los requerimientos del cura, sucede a la inversa ( $\left.\mathrm{F}_{5}\right)$.

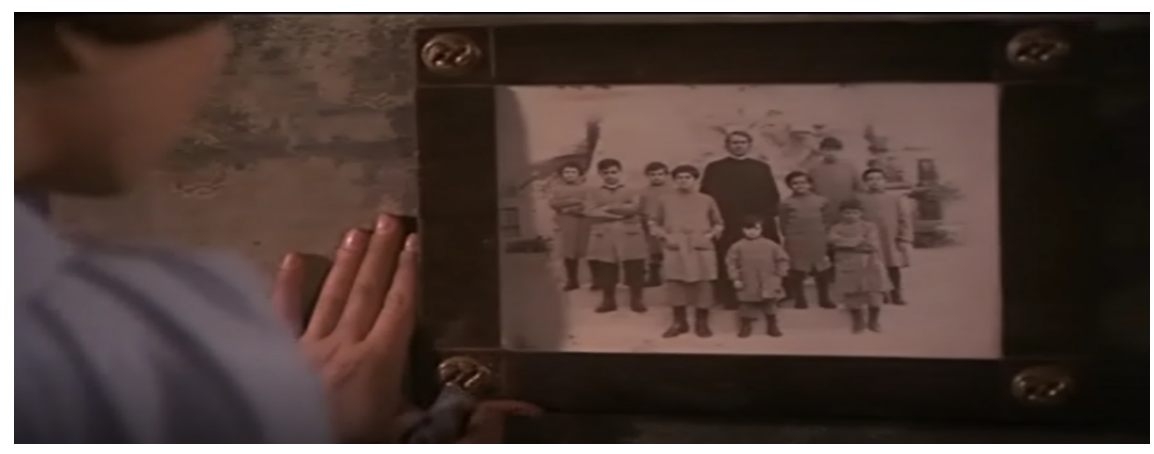

F4

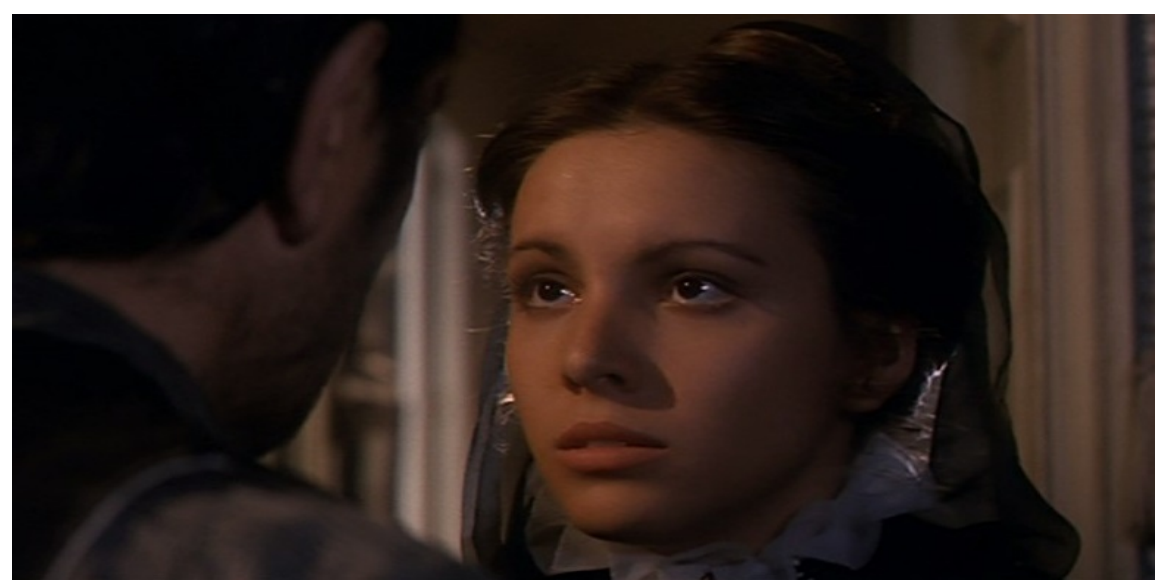

F5

Esta secuencia fílmica, la de la narración en primera persona junto a las imágenes fotográficas, sustituye al narrador heterodiegético en el texto escrito. Aquí, después de la salida de Amparo de la casa del sacerdote, la voz narrativa se pregunta, con un fin aleccionador, qué fue de aquel eclesiástico don Pedro Polo:

¿Qué se hizo de la brillante posición de don Pedro Polo bajo los auspicios de las señoras monjas de San Fernando? ¿Qué fue de su escuela famosa, donde eran desbravados todos los chicos de aquel barrio? [...] iEnseñanza grande y triste que debieran tener muy en cuenta los que han subido prontamente al catafalco de la fortuna! Porque si rápido fue el encumbramiento de aquel señor, más rápida fue su caída [...]! (Pérez Galdós, 1986, p. 92). 


\section{Conclusiones}

A lo largo del presente artículo hemos podido constatar cómo la película de Pedro Olea, Tormento, basada en la novela homónima que Pérez Galdós publicara noventa años antes, es prueba de un cine donde la imagen se establece como soporte de la palabra y viceversa. De esta manera, el encuentro de la palabra y la imagen en la filmación de Olea nos sirve de fundamento para hablar de un cine, el suyo, encausado en la teoría de la recepción donde la labor del creador y la del espectador se hacen indispensables para construir, comunicar e interpretar ciertos sentidos y significaciones.

De esta manera, el director vasco realiza una valiosa reescritura de un texto narrativo clásico de la literatura española que, en su caso, resulta ser una obra de gran potencialidad transgresora en una época que, recordemos, viene marcada por los años finales de la dictadura franquista. Desde esta perspectiva, podemos decir que Olea pone en escena no tanto el texto literario como su particular lectura y exégesis de dicho texto, lo que consigue mediante la imagen, dada a partir de los procedimientos técnicos cinematográficos, y la palabra, expresada no solamente a través de la voz de los personajes sino, también, por medio de los valores simbólicos y metafóricos de los gestos, las miradas y los movimientos en aquellos.

Estamos, pues, ante una obra fílmica ambigua y compleja donde se sugiere más de lo que realmente se observa a primera vista, lo que potencia y abre la imaginación del espectador descubriéndose, así, las enormes potencialidades creativas de Olea. En su película Tormento, el poder de la palabra queda reforzado con lo visual, pero también con lo auditivo armándose, por tanto, escenas y secuencias de gran expresividad y dramatismo. Por algo no es un asunto trivial que el Tormento oleaniano haya recibido el reconocimiento de la crítica.

Se trata, pues, de un film donde se rinde un culto casi reverencial al encuentro entre la palabra y la imagen mediante el que se comunican explícita e implícitamente los deseos, las ambiciones, las envidias, las hipocresías y las apariencias por las que se mueve el ser humano en sociedad. Por consiguiente, la obra de Olea es el ejemplo de un cine poético porque el director vasco posee un talento excepcional para confeccionar las personalidades, los diálogos y los aspectos de unos personajes quienes, a través de sus gestos, miradas y palabra, 
ponen al descubierto prejuicios sociales y clasistas, cuestiones religiosas y de sexo y, sobre todo, un ansia de libertad en el hombre y en la mujer que ya era imparable. Su valentía para sugerir ciertos temas y su capacidad para cautivar al espectador desde el mismo principio de la película cuando el coche de caballos se dirige a la estación - momento en el que la soberbia actriz Concha Velasco nos deja ver bien claro quién es la que manda en el matrimonio Bringas-, hace que haya sido calificado como "algo más que un artesano” (Galán, junio de 2015).

En definitiva, el gran mérito de Olea en Tormento radica en su habilidad para saber utilizar la imagen y la palabra de manera efectiva y en el momento pertinente con el objeto de contar con visos de verosimilitud una historia de pasiones, deseos e intrigas evocando nuevos valores y significados de las cosas y el mundo.

\section{Referencias bibliográficas}

Albèra, F. (Comp.) (1998). Los formalistas rusos y el cine: la poética del filme. Barcelona: Paidós.

Baldelli, P. (1966). El cine y la obra literaria. La Habana, Cuba: Ediciones ICAIC. Bazin, A. (2004). ¿Qué es el cine? Madrid: Rialp.

Bettetini, G. (1984). La conversación audiovisual: Problemas de la enunciación filmica y televisiva, trad. Talens Jenaro. Madrid: Cátedra.

Bluestone, G. (1968). Novels into Film. Berkeley: University of California Press.

Cepedello, $\mathrm{M}^{\mathrm{a}}$ P. (2011). La homodiégesis fílmica o la imposibilidad de la adaptación: de $L^{\prime}$ élégance du hérisson a Le hérisson. Cuadernos de Filología Francesa, 22, 179-191.

Chatman, S. (1990). Historia y Discurso. La estructura narrativa en la novela y en el cine. Madrid: Taurus.

Díaz Navarro, E. (2016). El crepúsculo de los héroes en Beltenegros: de la novela de Antonio Muñoz Molina al film de Pilar Miró. Castilla. Estudios de Literatura, 7, 69-84.

Doležel, L. (1986). Semiotics of Literary Communication. Strumenti Critici, 1, 548.

Doležel, L. (1990). Occidental Poetics. Tradition and Progress. Lincoln: University of Nebraska Press.

Eikhenbaum, B. (1998). Problemas de cine-estilística. En F. Albèra (Comp.), Los formalistas rusos y el cine: la poética del filme (pp. 45-75). Barcelona: Paidós. 
Galán, D. (junio de 2015). Algo más que un artesano. El País. Recuperado en: https://elpais.com/cultura/2015/06/01/actualidad/1433180509_18443 8.html.

Gómez, I. y González Álvarez, J.M. (2017). La adaptación en la era intermediática: textos, pantallas e industria. Fotocinema. Revista científica de cine y fotografía, 14, 5-18.

Gómez López, E. (2010). De la literatura al cine: aproximación a una teoría de la adaptación. Revista de filología alemana, 2, 245-255.

González de Canales Carcereny, J. (2017). El cine de Albert Serra: apropiación y reinterpretación fílmica de los clásicos literarios. Fotocinema. Revista científica de cine y fotografía, 14, pp. 83-98.

Gubern, R. (1981). La censura: función política y ordenamiento jurídico bajo el franquismo (1936-1975). Barcelona: Península.

Hermosilla, $M^{a}$ A. (1992). La técnica objetiva en un relato de Ignacio Aldecoa: En el kilómetro 40o. En J. A. Hernández Guerrero (Ed.), Teoría, Crítica e Historia Literaria, Seminario de Teoría de la Literatura (pp. 315-330). Cádiz: Servicio de Publicaciones Univ. de Cádiz, Cádiz.

Iser, W. (1989). La estructura apelativa de los textos. En R. Warning (Ed.), Estética de la recepción (pp. 133-148). Madrid: Visor, Madrid.

Jakobson, R. (1973). Décadence du cinéma? En R. Jakobson \& Z. Todorov (Aut.), Questions de poétique (pp. 105-122). Paris: Seuil.

Mañas, $M^{a}$ (1990). Benito Pérez Galdós y Pedro Olea: dos visiones para un mismo Tormento. 1616: Anuario de la Sociedad Española de Literatura General y Comparada, 8, 135-143.

Metz, C. (1964). Le cinéma: langue ou langage. Communications, 4, 52-64.

Metz, C. (2002). Problemas actuales de teoría del cine. En C. Metz (Aut.), Ensayos sobre la significación en el cine (1986-1972), II (pp. 180-221). Barcelona: Paidós.

Navarrete-Galiano, R. (2003). Galdós en el cine español. Madrid: T\&B Editores.

Navarrete-Galiano, R. (2015). Galdós y la censura del cine español. FILMHISTORIA Online, Vol. XXV (1), 35-44.

Pardo, P. J. y Sánchez Zapatero, J. (Coords.).(2014). Sobre la adaptación y más allá: trasvases filmoliterarios. Salamanca: Ediciones Universidad de Salamanca.

Pasolini, P. y Rohmer, E. (1970). Cine de poesía contra cine de prosa, trad. Joaquín Jordá. Barcelona: Anagrama.

Peña-Ardid, C. (1992). Literatura y cine. Una aproximación comparativa. Madrid: Cátedra.

Perales, L. (julio de 2013). Concha Velasco: Nadie me habla en casa. Me paso el día estudiando. El Cultural. Recuperado en: http://www.elcultural.com/revista/escenarios/Concha-Velasco/33201. 
Pérez Bowie, J. A. (2008). La adaptación como encrucijada. En J. A. Pérez Bowie (Ed.), Leer el cine: la teoría literaria en la teoría cinematográfica (pp. 185-204). Salamanca: Ediciones Universidad de Salamanca.

Pérez Bowie, J. A. (2010). Sobre reescritura y nociones conexas. Un estado de la cuestión. En J. A. Pérez Bowie (Ed.), Reescrituras fílmicas: nuevos territorios de la adaptación (pp. 21-43). Salamanca: Ediciones Universidad de Salamanca.

Pérez Galdós, B. (1986). Tormento. Madrid: Alianza.

Pol Galiñanes, T. (2005). Un Tormento literario, un Tormento cinematográfico: la novela de Galdós y la versión de Pedro Olea. En Y. Arencibia, Ma Escobar \& R. Ma Quintana (Eds.), Actas del VIII Congreso Internacional de Estudios Galdosianos (pp. 788-798). Las Palmas de Gran Canaria: Cabildo Insular de Gran Canaria.

Quinn, P. P. (2017). Ensayo de un crimen. De la página a la pantalla. Fotocinema. Revista científica de cine y fotografía, 14, pp. 43-57.

Sklovski, V. (1998). Poesía y prosa en el cine. En F. Alberá (Comp.), Los formalistas rusos y el cine. La Poética del filme (pp. 135-138). Barcelona: Paidós.

Villanueva, D. (2008). Autobiografía (Camilo José Cela) y biografía (Ricardo Franco) de Pascual Duarte. En P. Poyato (Ed.), El realismo y sus formas en el cine rural español (pp. 51-84). Córdoba: Diputación de CórdobaAyuntamiento de Dos Torres.

Villanueva, D. (2008). Imágenes de la ciudad: poesía y cine, de Whitman a Lorca. Valladolid: Ediciones Universidad de Valladolid.

Zecchi, B. (Ed.). (2012). Teoría y Práctica de la adaptación filmica. Madrid: Editorial Universidad Complutense.

\section{Filmografía}

Olea, P. (1974). Tormento. España: José Frade P.C. 